\title{
Contributos da gestão visual para análise de tendências
}

Alessandro Mateus Felippe

Mestre, Universidade do Estado de Santa Catarina / alessandro@fiodameada.me Orcid: 0000-0001-6856-3991 / lattes

\section{Sandra Regina Rech}

Doutora, Universidade do Estado de Santa Catarina / sandra.rech@udesc.br Orcid: 0000-0002-0062-6914/ lattes

\section{Icléia Silveira}

Doutora, Universidade do Estado de Santa Catarina / icleiasilveira@gmail.com Orcid: 0000-0003-4493-9768/ lattes

Enviado: 31/07/2020 // Aceito: 09/12/2020 


\title{
Contributos da gestão visual para análise de tendências
}

\begin{abstract}
RESUMO
Este texto, fragmento integrante da investigação de mestrado em andamento, possui como temática central a aproximação teórica-conceitual entre tendências e gestão visual, objetivando qualificar o método de análise de tendências proposto por Dragt (2017) a partir de princípios e ferramentas da gestão visual. Em termos metodológicos, o artigo se desenha nos momentos de conceituar termos importantes por meio da Revisão Bibliográfica, bem como a coleta, redução, categorização e interpretação de dados via Análise Qualitativa de Dados. Ademais, classifica-se o texto como sendo de natureza básica, qualitativa e com objetivos descritivos. Os resultados alcançados demonstram que os princípios e as ferramentas da gestão visual agregam diferentes vantagens ao processo, tais como inovação, agilidade e incentivo a colaboração dos participantes do envolvidos na análise de tendências.
\end{abstract}

Palavras-chave: análise de tendências. Gestão visual. Método. 


\title{
Contributions of visual management to trend analysis
}

\begin{abstract}
This text, a fragment of the in progress master's research, has as main theme the theoretical-conceptual approach between trends and visual management, aiming to qualify the trend analysis method proposed by Dragt (2017) from visual management principles and tools. In methodological terms, the article is designed in the moments of conceptualizing important terms through the Bibliographic Review, as well as the collection, reduction, categorization and interpretation of data. data collection/reduction/categorization and interpretation through Qualitative Data Analysis. Furthermore, the text is classified as being of a basic, qualitative nature and with descriptive objectives. The results achieved demonstrate that the principles and tools of visual management add different advantages to the process, such as innovation, agility and encouraging the collaboration of the participants of those involved in the trend analysis.
\end{abstract}

Keywords: trend analysis. Visual management. Method. 


\title{
Contribuciones de la gestión visual al análisis de tendencias
}

\begin{abstract}
RESUMEN
Este texto, fragmento integral de la investigación del máster en curso, tiene como tema central el abordaje teóricoconceptual entre tendencias y gestión visual, con el objetivo de calificar el método de análisis de tendencias propuesto por Dragt (2017) a partir de principios y herramientas de gestión visual. . En términos metodológicos, el artículo se diseña en los momentos de conceptualización de términos importantes a través de la Revisión Bibliográfica, así como la recolección, reducción, categorización e interpretación de datos vía Análisis Cualitativo de Datos. Además, el texto se clasifica como de carácter básico, cualitativo y con objetivos descriptivos. Los resultados obtenidos demuestran que los principios y herramientas de la gestión visual añaden diferentes ventajas al proceso, como la innovación, la agilidad $y$ el fomento de la colaboración de los participantes de los implicados en el análisis de tendencias.
\end{abstract}

Palabras clave: análisis de tendencias. Manejo visual. Método. 


\section{INTRODUÇÃO}

A chamada Sociedade da Informação (CASTELLS, 2009), conceito postulado no final do século $X X$, entende que as relações sociais são construídas a partir da troca de informações, sendo esses dados de extrema importância para o desenvolvimento da sociedade. Desta maneira, a informação possui um caráter de protagonismo nas interações culturais, políticas, educacionais, econômicas, dentre outras, uma vez que possui diferentes origens, finalidades e têm como fator de influência a capacidade de alterar e influenciar diferentes lógicas de produzir e consumir bens.

Por isso, as áreas do conhecimento que objetivam coletar, analisar e interpretar a complexidade social tem papel crucial no entendimento do comportamento humano, manifestações culturais e lógicas paradoxais do consumidor final, seja para compreender anseios de consumo de maneira geral, seja para a prototipação de soluções específicas. Esse desafio se complexifica ao passo que a quantidade de informações produzidas, e que precisam ser analisadas, aumenta de forma exponencial, conforme frisa Luciana Stein, diretora de uma empresa referência na área de análise de tendências na América do Sul e Central (TRENDWATCHING, 2020).

Considerando esse contexto metaforicamente líquido (BAUMAN, 2011) no qual há o surgimento constante de informações, esse texto problematiza a análise de tendências e como esse campo de saber pode ser qualificado através de abordagens visuais, amparado em vantagens como: visualizar grande quantidade de informações, tornar deteminado projeto dinâmico, inovador e com grande incentivo ao engajamento/ participação de pessoas e gerar fluxo contínuo de trabalho e resultados. Em outras palavras, o problema deste artigo se configura em: como qualificar o modelo 
proposto por Dragt (2017) para análise de tendências a partir de princípios e ferramentas da gestão visual?

\section{METODOLOGIA}

Aqui, classifica-se a pesquisa em termos científicos através do uso de métodos, técnicas e procedimentos, uma vez que a metodologia científica é vista enquanto um meio para "descobrir respostas para problemas mediante o emprego de procedimentos científicos" conforme destaca Gil (2008, p. 42). Dessa maneira, os passos metodológicos compreendem pesquisa com finalidade básica, pois objetiva "aumentar e/ou gerar conehcimentos novos, construir teorias" sem aplicação prática prevista (ZAMBERLAN, 2014, p. 93).

Do ponto de vista da abordagem do problema, classificase como qualitativa. Segundo Gil (2008, p. 15), a abordagem qualitativa "considera que há uma dinâmica entre o mundo real e o sujeito", implicando uma interpretação e construção de significados a partir dos dados obtidos ao longo do estudo. Do ponto de vista dos objetivos almejados, consideram-se de cunho descritivo, já que esse tipo "visa descrever as relações entre variáveis" (SILVEIRA, 2018, p. 17) trabalhando com o relato de algum fato ou fenômeno.

$\mathrm{Na}$ sequência, para coleta de dados, valeu-se da metodologia de Revisão Bibliográfica, apresentando uma articulação teórica e conceitual entre os diversos autores a fim de responder a intenção proposta na introdução. Conforme Lakatos e Marconi (2017), essa metodologia permite entrar em contato com o referencial teórico publicado, seja em monografias, teses, livros ou mesmo em materiais audiovisuais, isto é, através da revisão da bibliografia, podese entender o que já foi pesquisado, principais conclusões e oportunidades de novas abordagens sobre um mesmo assunto. Para a análise dos dados coletados, utilizou-se a 
metodologia de Análise Qualitativa de Dados, sendo definido como um processo articulado com as etapas de redução, categorização e interpretação de dados (GIL, 2017; SILVEIRA, 2018; GIL, 2008).

Num desenho metodológico, após definidos os conceitos de análise de tendências e gestão visual, apresenta-se uma síntese de vantagens, princípios e ferramentas de gestão visual na sessão redução e categorização de dados; posteriormente, os dados foram aplicados e interpretados no método de análise de tendências proposto por Dragt (2017) na sessão interpretação de dados, resultando na qualificação que a gestão visual pode trazer para a análise de tendências apresentado no Quadro 5.

Por fim, este texto se configura enquanto resultado parcial da investigação de mestrado em andamento, manifestando fragmentos teóricos do segundo capítulo e sínteses de métodos de análise de tendências e de vantagens, princípios e ferramentas da gestão visual que compoem o quarto capítulo da referida dissertação ${ }^{1}$.

\section{CONCEITOS}

\subsection{Análise de tendências}

A palavra tendência é polissêmica e é compreendida enquanto sinônimo de movimento, novidade, antecipação, incerteza, fotografia da sociedade e estar em voga em determinado recorte de tempo e espaço (CAMPOS; WOLF, 2018; ERNER, 2015; DRAGT, 2017; RAYMOND, 2010; RECH, 2013; RECH; GOMES, 2016). Neste sentido, pode ser vista como "fenômenos que fornecem evidência tangível das mudanças sociais, relacionais e culturais" e possuem um "ciclo de vida intricado, em constante evolução" (RECH, 2013, p. 
109). Neste sentido, a partir de uma taxonomia, as tendências podem ser divididas em duas principais categorias, apresentados no Quadro 1.

Quadro 1. Classificação das tendências a partir de parâmetros de diferenciação

\begin{tabular}{|l|l|l|}
\hline & Macrotendência & Microtendências \\
\hline Adoção & Ampla & Restrita \\
\hline Pertencimento & Geral & Particular \\
\hline Duração & Longa & Breve \\
\hline Impacto & Substancial & Sutil \\
\hline Difusão & Mais lentamente & Mais velozmente \\
\hline Previsibilidade & Difícil & Fácil \\
\hline Base sociocultural & Evidente & Oculta \\
\hline
\end{tabular}

Fonte: Campos (2020).

Com viés histórico e, também, contemporâneo, "uma tendência (no sentido geral da palavra) é a inclinação predisposta para algo, alguém ou alguma situação que provavelmente acontecerá no futuro próximo". Ou seja, é um paradigma que direciona o olhar, o pensamento e as atitudes da sociedade para determinada direçã-o, podendo se concretizar, ou não. De forma complementar, a palavra tendência aborda alteridade, gerando uma atmosfera de "[a] finitude; ou seja, uma situação que será alcançada; e [b] futurologia; isto é, sugerindo que a situação acontecerá no futuro" (CAMPOS; WOLF, 2018, p. 19).

Já a análise de tendências é definida como um conjunto de métodos, procedimentos e ferramentas para identificação, compreensão e difusão das tendências. As autoras Maioli e Presotto (2012, p. 24) afirmam que para haver a análise de tendências "devemos realizar sempre uma aproximação com diversas metodologias, em um caráter multidisciplinar". Dessa forma, vale-se de estudos do tipo etnográficos, observação participante verificando inovações impulsionadas pelos trendsetters (definidos como promotores das 
tendências), instrumentos de trabalho de campo (qualitativos e quantitativos) e pesquisas secundárias com base semiótica.

Rech e Silveira (2017, p. 4) apontam que a análise de tendência é pautada numa lógica transdisciplinar, uma vez que enquanto área, mescam-se "procedimentos e conceitos de outras disciplinas e incorporam as oscilações dos comportamentos e dos parâmetros de consumo" permitindo a observação de padrões de repetição que podem dar indícios da emergência e arquitetura de tendências.

Dessa forma, o foco da análise de tendências não é guiado por sinais de um segmento específico, mas mesclam-se todos aqueles passíveis de gerar inovação, provocar mudanças e conceber cenários sobre o futuro. Considerando suas características e sua respectiva área de pesquisa, compreende-se que a utilização de tendências por profissionais de desenvolvimento de produtos de vários segmentos pressupõem insights, gerando competitividade na medida em que essas podem ser compreendidas como uma fotografia da realidade da sociedade, nas quais é possível capturar/intuir/deduzir o que está acontecendo, quais ideias estão dão movimento a determinados comportamentos num recorte de tempo-espaço (RECH; GOMES, 2016).

Não apenas isso, como também "uma tendência é um processo social que sugere uma mudança comportamental assente em mentalidades emergentes [...] revelando pistas importantes e sólidas para geração da inovação" (RECH; GOMES, 2016, p. 4). Logo, "não olhar" para as tendências pode significar ignorar pistas, sinais e manifestações de padrões de comportamento, novas tecnologias e diferentes desejos por parte de consumidores.

Além disso, é de extrema importância usar os resultados gerados a partir da identificação de determinadas tendências como fonte de informação e inspiração para concepção de 
produtos, uma vez que as tendências são "pontos focais do desejo, por meio dos quais indivíduos muito diferentes uns dos outros e sem comum acordo se descobrem as mesmas vontades" (ERNER, 2015, p. 9).

Neste sentido, entende-se que a pesquisa de tendências pode ser vista como um projeto, uma vez que se configura enquanto um esforço num determinado tempo e espaço com o objetivo de elaborar um produto/serviço/bem/resultado, possuindo um início e um fim previamente estabelecido, considerando a teoria sustentada pelos autores vistos até então. Logo, para realizar de forma metodológica a análise de tendências é preciso coletar, processar, organizar, sistematizar e interpretar um grande número de informações, chegando ao mapeamento de um porvir, de uma mentalidade coletiva que influencia comportamentos, múltiplas formas de sujeitos interagirem com o mundo e que faz um registro da sociedade; em outras palavras, a partir da gestão de muitas informações de macrotendências, comportamento de mercado e setores de referência, pode-se chegar ao resultado do mapeamento de uma tendência e fazer uso estratégico dessas informações (CAMPOS; RECH, 2016).

\subsection{Gestão visual}

É factual que nas últimas décadas se produziu uma alta quantidade de informações, em termos quali e quantitativos, quando comparado com toda a história da humanidade. Isso foi viável a partir do aperfeiçoamento da tecnologia (de produção e armazenamento), como a internet, sendo exequível romper, no sentido metafórico, as barreiras do tempo e espaço. Ou seja, hoje pode-se acessar uma informação oriunda de outro país (outro contexto/espaço físico) através de plataformas de pesquisa ou assistir uma 
vídeo-aula de uma escola de design de outro continente produzida há cinco anos atrás (outro tempo), catalisando um novo processo de tempo e espaço na produção e consumo de informações (CASTELLS, 2009).

Neste sentido, compreende-se que a informação detém uma grande valia para diferentes fins e o acesso a elas está cada vez mais democrático. Estas, considerando infinitas possibilidades, podem ser usadas para a inovação de um produto, reconhecer a ascensão de um novo mercado para o setor de marketing, entender comportamentos disruptivos de consumo, dar oportunidades educacionais a grupos sociais desprovidos deste acesso e, num sentido específico da presente pesquisa, desenvolver projetos de design, comunicação e bens de consumo. E, fazendo jus a este diagnóstico tão relevante, torna-se crucial realizar a gestão destas informações no contexto escolar, organizacional, empresarial, entretenimento, cultural, etc.

Teixeira (2018) parte deste input para refletir formas assertivas e estratégicas de realizar a gestão de informações dentro de projetos em organizações, pois o objetivo é promover uma visualização democrática, dinâmica e metodológica dos processos desenvolvidos a partir de informações. "Ao tornar os processos mais visuais, facilitamos a compreensão e a tomada de decisão; isso tende a deixar os projetos mais enxutos" (TEIXEIRA, 2018, p. 23) e incentivando processos de inovação e geração de insights.

Portanto, entende-se que os processos de codificação e decodificação de informações do ser humano pode ser mais fluido ao torná-lo visual, com repetições de padrões e estruturas metodológicas que proporcionem maior usabilidade. Conforme reflete Sibbet (2013, apud TEIXEIRA, 2018, p. 26), o principal benefício de realizar a gestão visual é que "projetistas, analistas de dados, tomadores de decisão 
e outras partes interessadas podem concentrar as suas atenções cognitivas e perceptivas, a partir da visualização das informações", isto é, os benefícios são nítidos quando tornase visual a organização de um grande número de informações.

Outra referência que contribui para o entendimento do conceito de gestão visual é Galsworth (2005), sob a ótica de estabelecer um espaço de trabalho organizado que elimina déficits de informação, ou seja, todos os dados e inputs são facilmente localizados e processados de forma quase intuitiva pelos interessados. Teixeira (2015, p. 59) versa acerca da gestão visual de projetos, tendo por definição um "conjunto de ações, ferramentas e modelos que visa promover maior visualização ao processo de desenvolvimento de projeto". Ou seja, agrega-se a esta lógica visual a elaboração de projetos em termos empresariais no desenvolvimento de produtos, serviços, soluções, design, dentre outros.

A falta de estruturação de modelos, processos, protocolos durante o desenvolvimento de um projeto pode resultar em "falhas de comunicação, erros de interpretação, frustrações e disputas, que atrapalham a evolução e a produtividade da equipe" (TEIXEIRA, 2018, p. 25). Em outras palavras, planejar o manejo das tarefas, responsáveis, prazos importantes, dentre outras questões que envolvem o desenvolvimento de um projeto gera maior enjagamento, rapidez e impulsos para a inovação. 


\section{ANÁLISE E DISCUSSÃO}

\subsection{Redução e categorização de dados - vantagens, diretrizes e ferramentas da gestão visual}

Assim, apresentam-se as vantagens de fazer uso da abordagem da gestão visual a partir das pesquisas realizadas por Tezel et al. (2009), sendo elas:

Quadro 2. Vantagens da gestão visual

\begin{tabular}{|l|l|}
\hline Transparência & $\begin{array}{l}\text { Permite acesso democrático as informações por todos os } \\
\text { profissionais envolvidos no processo. }\end{array}$ \\
\hline Disciplina & $\begin{array}{l}\text { Estimula as partes interessadas em manter os procedimentos } \\
\text { organizados }\end{array}$ \\
\hline Melhoria contínua & $\begin{array}{l}\text { Possibilita visualizar o processo como um todo de forma } \\
\text { frequente e qualificar o que for necessário }\end{array}$ \\
\hline Facilitação do trabalho & Torna a execução de demandas mais dinâmica e assertiva \\
\hline $\begin{array}{l}\text { "On-the-job training" } \\
\text { /treinamento em serviço, } \\
\text { em tradução livre }\end{array}$ & Facilita o aprendizado por meio da experiência visual \\
\hline $\begin{array}{l}\text { Criação e participação } \\
\text { compartilhada }\end{array}$ & $\begin{array}{l}\text { Engajamento dos participantes a partir do processo de } \\
\text { materialização física de soluções }\end{array}$ \\
\hline Gerenciamento por fatos & Uso de dados pragmáticos e específicos ao longo do processo \\
\hline Simplificação & $\begin{array}{l}\text { Redução e fragmentação de informações/protocolos/processos } \\
\text { completos }\end{array}$ \\
\hline Unificação & $\begin{array}{l}\text { Incentiva na construção do ambiente de trabalho mais } \\
\text { empático e organizado }\end{array}$ \\
\hline
\end{tabular}

Fonte: Tezel et al. (2009).

Além disso, Teixeira (2018) sublinha princípios para se propor a gestão visual de um projeto e que serão válidos para a análise e interpretação dos dados posteriormente, detalhados a seguir: 
Quadro 3. Princípios para criação de um modelo de gestão visual de projetos

\begin{tabular}{|l|l|}
\hline Princípios & Sugestões de aplicação \\
\hline $\begin{array}{l}\text { Visualização como eixo } \\
\text { condutor de processo }\end{array}$ & $\begin{array}{l}\text { Desenvolver um conjunto de métodos e ferramentas com foco } \\
\text { na visualização. }\end{array}$ \\
\hline $\begin{array}{l}\text { Estabelecer e utilizar um } \\
\text { modelo de referência }\end{array}$ & $\begin{array}{l}\text { Padronizar o uso de um único modelo de desenvolvimento de } \\
\text { projetos. }\end{array}$ \\
\hline $\begin{array}{l}\text { Promover a visualização } \\
\text { de informações }\end{array}$ & $\begin{array}{l}\text { Utilizar paineis visuais em ambientes de projeto; criar fichas de } \\
\text { orientação de entrega. }\end{array}$ \\
\hline $\begin{array}{l}\text { Conduzir de forma } \\
\text { sistêmica }\end{array}$ & Indicar fluxos de entrada, de saída e de transformação. \\
\hline Focar no valor & Determinar o que é valor para os interessados. \\
\hline Gerar fluxo contínuo & $\begin{array}{l}\text { Promover fluxo contínuo do desenvolvimento de projeto, } \\
\text { principalmente pelo fluxo de informações }\end{array}$ \\
\hline $\begin{array}{l}\text { Promover a participação } \\
\text { coletiva }\end{array}$ & $\begin{array}{l}\text { Envolver os colaboradores fornecendo-lhes acesso a } \\
\text { informações. }\end{array}$ \\
\hline
\end{tabular}

Fonte: Adaptado de Teixeira (2018).

Além disso, a falta de estruturação de modelos, processos, protocolos durante o desenvolvimento de um projeto pode resultar em "falhas de comunicação, erros de interpretação, frustrações e disputas, que atrapalham a evolução e a produtividade da equipe" (TEIXEIRA, 2018, p. 25). Neste sentido, a partir de diferentes autores e teorias, apresenta-se um quadro síntese de ferramentas visuais no Quadro 4:

Quadro 4. Síntese ${ }^{4}$ de ferramentas visuais

\begin{tabular}{|c|c|c|}
\hline Ferramenta & Descrição e função & $\begin{array}{l}\text { Autor(es) de } \\
\text { referência }\end{array}$ \\
\hline $\begin{array}{l}\text { A3 } \\
\text { Storyboard }\end{array}$ & $\begin{array}{l}\text { Ferramenta que surgiu junto com } \quad \text { propostas do } \\
\text { Pensamento Lean/Enxuto para o chão de } \\
\text { fábrica/manufatura; os relatórios A3 evoluíram até se } \\
\text { tornarem um modelo padrão para a resolução de } \\
\text { problemas; a ideia é que esses painéis sejam fixados no } \\
\text { ambiente de produção para que todos tenham acesso. }\end{array}$ & Dennis (2010) \\
\hline $\begin{array}{l}\text { Business } \\
\text { Model } \\
\text { Generation - } \\
\text { BMG } \\
\text { (Canvas) }\end{array}$ & $\begin{array}{l}\text { É uma ferramenta para modelagem de negócios; seu } \\
\text { sucesso é devido ao pressuposto de que visualizar os } \\
\text { principais elementos em um único plano facilita perceber a } \\
\text { relação entre as partes de maneira global. }\end{array}$ & $\begin{array}{l}\text { Osterwalder, } \\
\text { Pigneur } \\
\text { (2011) }\end{array}$ \\
\hline $\begin{array}{l}\text { Cartões- } \\
\text { recado }\end{array}$ & $\begin{array}{l}\text { É uma ferramenta que sugere o uso de notas rápidas } \\
\text { contendo o nome da tarefa/processo a ser executado, o } \\
\text { responsável, data prevista para entrega, dentre outras } \\
\text { informações importantes. }\end{array}$ & $\begin{array}{l}\text { Amaral et al. } \\
(2011)\end{array}$ \\
\hline $\begin{array}{l}\text { Espaços para } \\
\text { acesso à } \\
\text { informação }\end{array}$ & $\begin{array}{l}\text { É a construção de espaços que permitam a visualização de } \\
\text { diferentes informações (como a sala do café, por } \\
\text { exemplo); isso foi viável após mapear diferentes empresas }\end{array}$ & $\begin{array}{ll}\text { Eppler, } & \text { Platts } \\
\text { (2009) } & \end{array}$ \\
\hline
\end{tabular}




\begin{tabular}{|c|c|c|}
\hline & m essa prática. & \\
\hline Fichas Lean & $\begin{array}{l}\text { E uma ferramenta que traz informações relevantes de } \\
\text { orietanções para os envolvidos na execução do projeto. }\end{array}$ & $\begin{array}{l}\text { Lean } \\
\text { Enterprise } \\
\text { Institute } \\
\text { (2007) }\end{array}$ \\
\hline $\begin{array}{l}\text { Foto-diário/ } \\
\text { diário } \\
\text { fotográfico }\end{array}$ & $\begin{array}{l}\text { Ferramenta que permite o registro contínuo de um } \\
\text { fenômeno a ser estudado, resultando em fotografias que } \\
\text { possuem relações com o usuário com conteúdos } \\
\text { subjetivos; também pode ser usado em pesquisas iniciais } \\
\text { de consumo, registros inspiracionais, provas de } \\
\text { modelagem ou experimentos de usabilidade. }\end{array}$ & $\begin{array}{l}\text { Sanches } \\
(2017) ; \text { Bona } \\
(2019)\end{array}$ \\
\hline Kanban & $\begin{array}{l}\text { É um dispositivo que oferece informações (nome da peça, } \\
\text { códigos, fornecedores, armazenamento etc.) e } \\
\text { instruções/status (to do, doing, done - por fazer, em } \\
\text { desenvolvimento, finalizado) importantes para a } \\
\text { compreensão de deteminada etapa do projeto; o termo } \\
\text { significa sinais ou quadro de sinais, em japonês. }\end{array}$ & $\begin{array}{l}\text { Teixeira, } \\
\text { Schoenardie, } \\
\text { Merino (2011) }\end{array}$ \\
\hline $\begin{array}{l}\text { Mood Chart/ } \\
\text { Mood Board }\end{array}$ & $\begin{array}{l}\text { Ferramenta que auxilia na representação visual de } \\
\text { conceitos a partir da colagem (física ou digital) de } \\
\text { diferentes imagens, idealizando o universo imagético do } \\
\text { projeto ou da solução simbolicamente. }\end{array}$ & Burdek (2006) \\
\hline $\begin{array}{lr}\text { Painel } & \text { de } \\
\text { estilo } & \text { de } \\
\text { vida/ } & \text { life } \\
\text { style } & \text { do } \\
\text { público-alvo }\end{array}$ & $\begin{array}{l}\text { Painel com objetivo de apresentar elementos que } \\
\text { apresentem o perfil do estilo de vida do futuro consumidor } \\
\text { da solução pensada; a selação de imagens envolvem } \\
\text { valores pessoais, sociais, produtos utilizados, dentre } \\
\text { outras informações que contribuam para a compreensão } \\
\text { do público-alvo; além do formato estático, pode ser } \\
\text { apresentado em formato de vídeo. }\end{array}$ & Baxter (2011) \\
\hline $\begin{array}{l}\text { Painel } \\
\text { Semântico }\end{array}$ & $\begin{array}{l}\text { Ferramenta que reúne imagens, expressões, recortes, } \\
\text { texturas e que comunica através de metáforas visuais; } \\
\text { pode ser usado como expressão do produto ou solução e é } \\
\text { desenvolvido por meio de colagem (física ou digital). }\end{array}$ & $\begin{array}{l}\text { Sanches } \\
\text { (2017) }\end{array}$ \\
\hline $\begin{array}{l}\text { Project Model } \\
\text { Canvas }\end{array}$ & $\begin{array}{l}\text { É uma ferramenta inspirada no Canvas e permite uma } \\
\text { compreensão visual dos conceitos do projeto, do } \\
\text { engajamento da equipe e da tomada de decisões; isso } \\
\text { contribui para o entendimento de que um painel pode } \\
\text { auxiliar de forma planificada e visual o planejamento geral } \\
\text { do projeto. }\end{array}$ & $\begin{array}{l}\text { Finocchio } \\
\text { Júnior (2013) }\end{array}$ \\
\hline $\begin{array}{l}\text { Sketchbook/ } \\
\text { caderno de } \\
\text { esboço) }\end{array}$ & $\begin{array}{l}\text { Ferramenta que possibilita um espaço físico para o registro } \\
\text { de aprendizados, dados, experimentação de ideias, dentre } \\
\text { outras possibilidades; pode ser materializado em um } \\
\text { caderno pequeno de uso pessoal. }\end{array}$ & $\begin{array}{l}\text { Seivewright } \\
\text { (2009) }\end{array}$ \\
\hline $\begin{array}{l}\text { Trend book/ } \\
\text { trend report/ } \\
\text { caderno de } \\
\text { tendências }\end{array}$ & $\begin{array}{l}\text { Instrumento de comunicação, difusão e tradução de } \\
\text { tendências; seu formato não obedece um padrão regular e } \\
\text { frequentemente é adaptado conforme a tendência em si ou } \\
\text { a área investigada. }\end{array}$ & $\begin{array}{l}\text { Dragt }(2017) ; \\
\text { Flores }(2019)\end{array}$ \\
\hline
\end{tabular}

Fonte: Autor (2020)

Salienta-se, por fim, que há uma fonte inesgotável de outras ferramentas visuais; contudo, esta síntese se propôs a apresentar ferramentas de uso recorrente na área de 
desenvolvimento de projetos/produtos e design de moda encontrados na literatura pertinente e que dizem respeito a problematização central da dissertação.

\subsubsection{Interpretação de dados - gestão visual aplicada à análise de tendências}

O modelo de análise de tendências, sintetizado da obra How to research trends proposto por Dragt (2017), configurase como conteúdo de relevância e foco para análise deste texto. Neste tópico, apresenta-se a estrutura desenhada pela autora dividida em três principais fases (scan, analyse e apply $\left.{ }^{2}\right)$ e, em seguida, detalham-se os passos que compõe cada fase; posteriormente, tais passos serão articulados e interpretados com os princípios apresentados no quadro 3 e as ferramentas detalhadas no quadro 4, por meio da abordagem de análise qualitativa de dados (GIL, 2017; 2008).

Para Dragt (2017, p. 14), os métodos de pesquisa geralmente buscam um novo conhecimento, uma vez que se configuram como uma "investigação sistemática de um determinado tópico, a fim de apurar fatos e chegar a novas conclusões". Dessa forma, considerando a complexidade e a interconectividade do mundo atual, a análise de tendências se torna um desafio para profissionais e empresas, uma vez que implica a observação, detalhamento e monitoramento constante de mudanças em diversos fatores como tecnologia, economia, política, sociedade, dentre outros.

De forma semelhante, o pesquisador Buck (2019, p. 110) discorre que são inúmeras as possibilidades para se propor a análise de tendências, visto que "um trabalho eficiente com as tendências significa mais do que apenas a identificação de cada tendência e seu aproveitamento relacionado a produtos". Logo, valer-se de informações de tendências para 
balizar decisões organizacionais está no mesmo patamar das chamadas políticas de inovação e/ou planos de negócios coorporativos com foco na inovação. Sendo assim, Buck (2019) apresenta as seguintes possibilidades abrangentes para a análise de tendências no contexto organizacional: (I) Estratégias de Futuro; (II) Estratégias de Negócios; (III) Estratégias de Portfólio; (IV) Estratégias de Posicionamento; (V) Estratégias de Marca; (VI) Estratégias de Marca; (VI) Estratégias de Transferência; (VII) Estratégias de Gruposalvo; (VIII) Estratégias de Organização; (IX) Estratégias de Cooperação. Em última instância, é importante o alinhamento no desenvolvimento de soluções com os valores e necessidades emergentes num determinado contexto social.

Dragt (2017, p. 14) define tendência como uma "direção da mudança de valores e necessidades que é impulsionada por forças e se manifesta de várias maneiras". Dito isso, durante o processo de análise de tendências é de grande relevância considerar a tríade passado-presente-futuro e suas mútuas forças, uma vez que a sociedade se vale do passado para guiar seu comportamento futuro. Por fim, o profissional que busca compreender o que significa determinada mudança na esfera social precisa ser criativo, persistente, ter um pensamento visual, ter fácil e rápido reconhecimento de sinais de mudanças e ser um bom contador de histórias (RECH; GOMES, 2016). 
Figura 1. Estrutura para análise de tendências

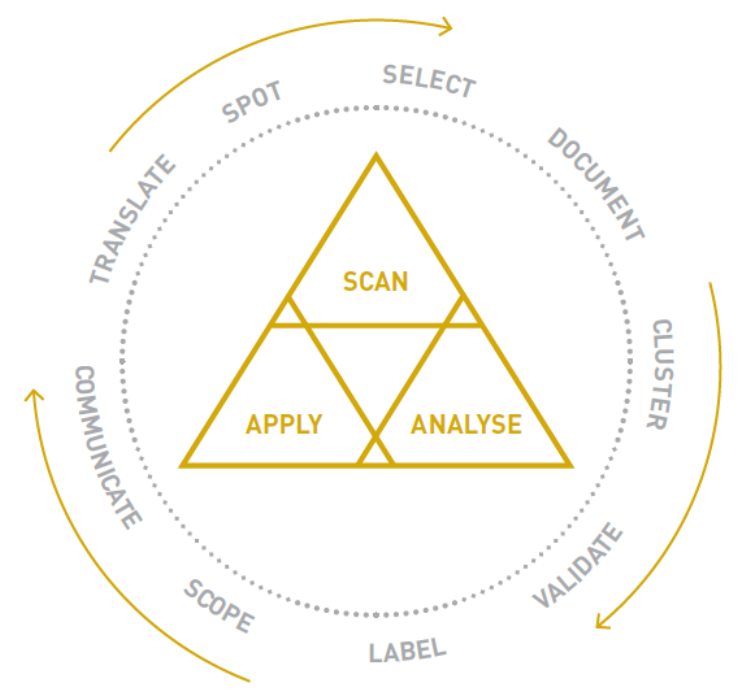

Fonte: Dragt, 2017.

De forma objetiva, a figura 1 apresenta a estrutura do método de análise de tendências organizado nas fases escaneamento, análise e aplicação e subdivido em nove 4 etapas, resultando em uma proposta metodológica circular, ou seja, inicia-se no passo spot e encerra-se na translate, sendo viável o início imediato na busca de novos sinais de mudanças caso o(a) pesquisador(a) perceba a necessidade.

De mandeira geral, a fase (a) escaneamento corresponde ao momento de olhar com atenção para a sociedade, mapeando e coletando todas as mudanças que estão acontecendo; é composta pelos passos denominados spot, select e document; a fase (b) análise busca compreender, numa abordagem interpretativa, o motivo dessas mudanças acontecerem, suas interconexões, relações, buscando entender os porquês e é estruturada por cluster, validate e label; por fim, na fase nomeada como (c) aplicação, após compreender e nomear determinadas tendências, propõe-se validar as tendências a partir da aplicação prática em problemas específicos, gerando insights, desenvolvimento 
produtos e inspirando soluções inovadoras; a fase é composta pelos passos chamados scop, communicate e translate.

Diante disso, entende-se que as duas primeiras fases pesquisam, de fato, mudanças na sociedade para compreensão e verificação de tendências emergentes. A terceira fase almeja a aplicabilidade dos resultados alcançados, resultando na inovação e solução de problemas específicos, seja em empresas, escolas, universidades, estúdios criativos, agências de comunicação ou outros espaços sociais que sejam influenciados por alterações tecnológicas, comportamentais, econômicas, políticas, ambientais...

\section{- Scan}

Nesse sentido, inicia-se a análise de tendências verificando/escaneando sinais e pistas de mudanças na sociedade através de diferentes perspectivas no passo 01 chamado spot, ou melhor, busca-se manifestações que vão contra a tradição e pensamento convencional de diferentes origens (cultura, música, arte, tecnologia, eventos, exposições, festivas, na rua...); neste momento, a quantidade se sobrepõe a qualidade de informações coletadas. Aqui podese pensar no uso da ferramenta visual foto-diário em conjunto com o sketchbook como meio de registrar a caça dos sinais (GLOOR, 2011) que são interpretados como pontos fora da curva, ou mesmo aquilo que está acontecendo/sendo desenvolvido na margem da sociedade (WEBB, 2016) e articulado com o princípio da gestão visual da visualização como eixo condutor de processo.

O passo 02 , denominado select, almeja selecionar os sinais de mudanças mais relevantes considerando a qualidade e não a quantidade; critérios de seleção também são feitos para melhor organização das informações; para essa seleção, perguntas-chave podem contribuir: O sinal é inovador? É 
inspirador? É fácil de entender e comunicá-lo? É considerado uma anomalia? Esse sinal é verdadeiro, é de confiança? Possui um impacto criativo? (DRAGT, 2017; GOMES, COHEN, FLORES, 2018). Neste momento, pode-se valer da ferramenta fichas lean, através da adaptação das mesmas conforme as perguntas-chave, oferecendo um espaço com respostas rápidas e objetivas acerca daquele sinal. Também, podem ser anexadas os materias coletados no passo anterior a partir da ferramenta foto-diário; o princípio adotado é a geração de fluxo contínuo, uma vez que é possível a atualização constante desse processo neste momento de seleção de sinais.

O passo 03, chamado document, corresponde ao momento de conhecer o contexto dos sinais selecionados de forma mais profunda; algumas perguntas podem facilitar: O que é isso? Como isso funciona? Qual foi a primeira vez que isso surgiu/apareceu/aconteceu? Quem é o criador? Isso pode ser relacionado com algum aspecto de qualidade de vida? Também é importante estabelecer fontes para futuros contatos acerca da informação. Por isso, pode-se implementar a ferramenta espaços para acesso à informação, uma vez pode-se ampliar os registros feitos no passo anterior, oferecendo uma ampla visualização daquilo que foi coletado; ademais, o princípio indicado na estruturação desse momento é, novamente, a visualização como eixo condutor.

\section{- Analyse}

O passo 04, chamado cluster, objetiva agrupar os sinais coletados por categorias que manifestam as mesmas necessidades e valores através do questionamento "por que isso ocorre?", ou seja, tenta-se encaixar diferentes peças de um grande quebra-cabeça para compreender as manifestações de tendências emergentes, uma vez que "uma tendência é, portanto, um padrão, uma forma" (FLORES, 
2019, p. 85); aqui torna-se importante a colaboração de outros pesquisadores na organização das informações, sobrepondo opiniões pessoais, através da discussão e reflexão (DRAGT, 2017; Nesse passo, pode-se valer da ferramenta painel semântico pela possibilidade de sobreposição e manuseio de diferentes informações, numa lógica processual e não definitiva; o princípio da promoção da participaçlão coletiva se faz presente, incentivando o trabalho colaborativo.

O passo 05, validate, aprofunda a coleta de informações acerca dos sinais coletados, buscando coerência, relevância, emergência e validação dos mesmos; dessa forma, levantase o máximo de informações sobre o dado coletado com o intuito de elaborar uma história coerente e singular; algumas perguntas podem ser feitas: Por que isso está acontecendo exatamente agora? Qual é a específica mudança no valor ou necessidade que esse sinal causa? Quem começou e quem está difundindo-o? Há alguma consequência disto para a futura qualidade de vida das pessoas? (DRAGT, 2017). Além da ampliação dos registros nas fichas lean, sugere-se também o uso do painel de lifestyle e adoção da ferramenta $A 3$ storyboard, por permitirem a narração coerente dos fatos que estão sendo interpretados. O princípio adotado nesse momento é o foco no valor, uma vez que é preciso validar os valores e necessidades importantes para a compreensão da tendência, numa perspectiva qualitativa para o processo de análise de tendências (RECH, CARDIM, 2016).

O passo 06, label, propõe-se nomear - verbal e visualmente - a tendência pesquisada, através da habilidade de contar histórias (que faça sentido e cause impacto positivo), estabelecendo um trend name e um trend image ${ }^{3}$; o desafio é criar um nome que traduza toda complexidade, conexão e amplitude de uma tendência; para a esfera visual, é importante selecionar uma imagem que valha por mil 
palavras para traduzir todas as sensações, sentimentos, valores e necessidades da tendência; sugere-se, para colaborar com esse passo, a adoção das ferramenras moodboard, painel semântico e painel de lifestyle, uma vez oportunizam resumir visual e verbalmente todas as informações relevantes para a compreensão da tendência e construção do trend image e do trend name; o princípio para a escolha das ferramentas é o estabelecimento e uso de um modelo de referência, pois estrutura uma maneira estratégica para o passo de nomear a tendência.

\section{- Apply}

Na última fase, o passo 07, chamado scop, objetiva gerar insights a partir das tendências prospectadas, tendo diferentes objetivos enquanto contributo na resolução de problemas específicos para organizações, profissionais, pesquisadores e estudantes; em outras palavras, aqui é o momento de entender como usar as tendências para um desafio. Além disso, nesse passo se realiza um monitoramento em busca de novas mudanças na sociedade que corroborem, adaptem ou qualifiquem a tendência investigada. Nesse caso, pode-se fazer uso das ferramentas canvas e project model canvas pois permitem a prototipação rápida de soluções, o desenho de modelos de negócios e a tomada rápida de decisões; também, sugere-se a introdução das ferramentas kanban e cartões recado, pois possibilitam a visualização do status geral de cada etapa do processo. Além do uso de um modelo de referência na escolha de ferramentas, a promoção da participação coletiva também se materializa como princípio ao passo que todos podem colaborar nesse desenho de soluções.

O passo 08 , communicate, busca comunicar os principais resultados verificados na análise de tendências, considerando as características específicas do desafio a ser resolvido, 
briefing ou público a quem se destina essa informação. Logo, torna-se relevante definir o equilíbrio entre o que se deseja dizer e o que a audiência (cliente, agência contratante, escola...) quer ouvir. Por isso, é relevante alinhar de que forma a história da tendência será contada: texto, imagem, vídeo, workshop, apresentação, dentre outras possibilidades. Aqui sugere-se o resgate de todas as ferramentas utilizadas até agora, extraindo os elementos que merecem destaque para a coerência da história contada e inseridas no trend book; o princípio verificado nesse passo é a visualização das informações pertinentes.

Por fim, o passo 09, translate, promove a tradução/difusão da tendência diagnosticada com outras pessoas, procurando convergir, divergir e qualificar ideias para uma melhor compreensão do futuro, impulsionando os primeiros passos de mudanças e inovações. Através de novos valores e necessidades, é possível cocriar soluções com o cliente, seja um produto, serviço, campanha publicitária, evento ou até mesmo posicionamento/diferencial de mercado para uma nova marca. Aqui sugere-se a adoção das ferramentas de espaços para acesso à informação e sketchbook, pois essa permite a colaboração e troca de ideias entre os participantes e aquela pode ser usada no registro de novas percepções. Os princípios aplicados aqui dizem respeito ao foco no valor, a participação coletiva e visualização como eixo condutor do processo.

Contudo, como apurado pela bibliografia, ao optar pela administração de um projeto a partir da gestão visual, isso requer o entendimento das demandas específicas de cada projeto; aqui se buscou apresentar uma breve reflexão teórica-conceitual dos contributos dessa abordagem para a análise de tendências, a partir do estudo do método proposto por Dragt (2017) com três principais momentos: o 
escaneamento, a análise e a aplicação de informações de tendências. Além disso, como já salientado, este texto se configura enquanto parte integrante de resultados parciais da investigação de mestrado em andamento.

Quadro 5. Aplicação da gestão visual na análise de tendências

\begin{tabular}{|c|c|c|c|}
\hline Fase & Passo & Princípio adotado & Ferramenta sugerida \\
\hline \multirow[t]{3}{*}{ escaneamento } & spot & $\begin{array}{lrr}\text { visualização } & \text { como } & \text { eixo } \\
\text { condutor de processo } & \\
\end{array}$ & foto-diário e sketchbook \\
\hline & select & geração de fluxo contínuo & fichas lean e foto-diário \\
\hline & document & 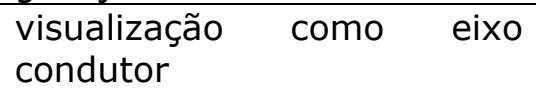 & $\begin{array}{lll}\text { espaços para acesso à } \\
\text { informação }\end{array}$ \\
\hline \multirow[t]{3}{*}{ análise } & cluster & participação coletiva & painel semântico \\
\hline & validate & geração de valor & $\begin{array}{l}\text { painel de lifestyle e A3 } \\
\text { storyboard }\end{array}$ \\
\hline & label & $\begin{array}{l}\text { estabelecimento e utilização } \\
\text { de modelo de referência }\end{array}$ & 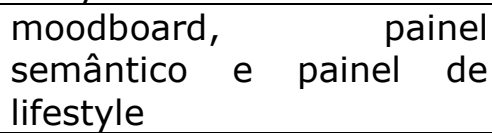 \\
\hline \multirow[t]{3}{*}{ aplicação } & scope & $\begin{array}{l}\text { estabelecimento e utilização } \\
\text { de modelo de referência e } \\
\text { participação coletiva }\end{array}$ & $\begin{array}{l}\text { Canvas, project } \text { model } \\
\text { canvas, kanban e cartões } \\
\text { recado }\end{array}$ \\
\hline & communicate & $\begin{array}{l}\text { Promoção da visualização de } \\
\text { informações }\end{array}$ & Trendbook \\
\hline & translate & $\begin{array}{l}\text { foco no valor, participação } \\
\text { coletiva e visualização como } \\
\text { eixo condutor de processo }\end{array}$ & $\begin{array}{l}\text { espaços para acesso à } \\
\text { informação e sketchbook }\end{array}$ \\
\hline
\end{tabular}

Fonte: o autor (2020).

Em última instância, finaliza-se essa análise com o quadro 5 , sintetizando os principais resultados alcançados por meio da articulação teórica-conceitual das fases e passos do modelo de análise de tendências, juntamente com o princípio adotado e a ferramenta sugerida, oriundos da gestão visual.

\section{CONSIDERAÇÕES FINAIS}

À guiza de considerações finais, primeiramente pontua-se que é importante perceber os métodos de análise de tendências enquanto projetos; sendo assim, podem-se entendê-los enquanto projetos viáveis de serem geridos visualmente. Em segundo lugar, ratifica-se que esse tipo de 
investigação exige dos profissionais envolvidos constante dedicação na captação, organização, sistematização, interpretação e uso de informações; em outras palavras, é crucial planejar estrategicamente o processo de análise de tendências para alcançar resultados efetivos. Por isso, destaca-se a importância em fazer uso de princípios e ferramentas da gestão visual, pois os mesmos oferecem recursos para inovação, estruturação de fluxos de trabalho e incentivo a participação/enjagamento dos profissionais envolvidos.

Como terceiro ponto, sublinha-se que o objetivo geral de qualificar o modelo proposto por Dragt (2017) para análise de tendências com princípios e ferramentas da gestão visual foi alcançado e materializada no quadro 5, através da abordagem analítica de dados qualitativos, articulando os nove passos do método de análise de tendências com princípios e ferramentas de gestão visual reduzidos e categorizados a partir da literatura congruente. Finalmente, como quarto ponto, salienta-se que esse texto se configura como resultado parcial do capítulo IV da investigação de mestrado em andamento e não é visto como resultado definitivo, mas uma discussão em progesso acerca da análise de tendências e a gestão visual.

\section{Notas de fim de texto}

1 Dissertação em andamento qualificada pelo Programa de Pós-graduação em Design de Vestuário e Moda na Universidade do Estado de Santa Catarina com o título de Modelo conceitual de análise de tendências com base na gestão visual de projetos para o Fashion Lab - Coletivo Criativo em Blumenau/SC.

2 Escaneamento, análise e aplicação - em tradução livre.

${ }^{3}$ Nome da tendência e Imagem da tendência, em tradução livre. 
4 Optou-se pela não tradução dos nomes dos nove passos do método, por compreender que corre-se o risco de não manter o sentido original que a autora almejou.

\section{REFERÊNCIAS}

AMARAL, D. et al. Gerenciamento ágil de projetos: aplicação em produtos inovadores. São Paulo: Saraiva, 2011.

BAXTER, M. Projeto de produto: guia prático para o design de novos produtos. 3. ed. São Paulo: E. Blucher, 2011.

BONA, S. F. Método de Projeto de Coleção em Design de Moda: uma configuração para micro e pequenas empresas. 2019. 136p. Dissertação (mestrado) - Universidade do Estado de Santa Catarina, Centro de Artes, Programa de Pós-Graduação, Florianópolis, 2019. Disponível em: https://www.udesc.br/arquivos/ceart/id_cpmenu/6295/Disserta_ o_Sheila_Fernanda_Bona_15816930311845_6295.pdf. Acesso em: 25 jul. 2020.

BUCK, A. Diretrizes para a gestão de tendências: inovação e estética como fundamento para o sucesso profissional/ Alex Buck, Christoph Herrmann, Dirk Lubkovitz. Curitiba: PUCPRESS, 2019.

BURDEK, B. E. Design: história, teoria e prática do design de produtos. São Paulo: E. Blucher, 2006.

CAMPOS, A. Q. Taxonomia dos tipos de tendências: uma proposta concisa. Datjournal Design Art and Technology, v. 5, p. 313328, 2020. Disponível em: https://doi.org/10.29147/dat.v5i2.209. Acesso em: 20 jul. 2020.

CAMPOS, A. Q; RECH, S. R. Método para pesquisa de tendências: uma revisão do modelo Futuro do Presente. In: ModaPalavra eperiódico. v. 9, n.17, jan-jun, 2016. Disponível em: https://doi.org/10.5965/1982615x09172016027. Acesso em: 12 jul. 2020.

CAMPOS, A. Q.; WOLF, B. O Conceito de Tendência na Moda: significado, histórico, conotação. ModaPalavra e-Periódico. n.6, n.11, p. 11-30, jul-dez. Dossiê Estudos de Tendências e Branding de Moda, 2018. Disponível em: http://www.revistas.udesc.br/index.php/modapalavra/article/view/ 11754. Acesso em: 20 jul. 2020.

CASTELLS, M. A Sociedade em rede. 12. ed. São Paulo: Paz e Terra, 2009.

DENNIS, P. The remedy: bringing lean thinking out of the factory to transform the entire organization. United States of America: John Wiley \& Sons, Inc., 2010.

DRAGT, E. How to research trends: move beyong trend watching to kickstart innovation. BIS Publishers, 2017. 
EPPLER, M.; PLATTS, K.. Visual Strategizing: The Systematic Use of Visualization in the Strategic-Planning Process. Long Range Planning, [s.I], v. 42, n. 1, p. 42-74, 19 jan. 2009. Trimestral. Disponível em: http://www.sciencedirect.com/science/article/pii/S0024630108001 180. Acesso em: 26 jul. 2020.

ERNER, G. Sociologia das Tendências. São Paulo: Editora G. Gili, 2015.

FINOCCHIO JÚNIOR, F. Project Model Canvas: gerenciamento de projetos sem burocracia. Rio de Janeiro: Elsevier, 2013.

FLORES, A. M. M. Jornalismo de inovação: os Estudos de Tendências como ferramenta de pesquisa. 2019. 237p. Tese (doutorado) - Universidade Deral de Santa Catarina, Centro de Comunicação e Expressão, Programa de Pós Graduação em Jornalismo, Florianópolis, 2019. Disponível em: https://readymag.com/Miuxapop/jornalismo/. Acesso em: 13 jul. 2020.

GALSWORTH, G. Visual Workplace: visual thinking. Portland: Visual-lean Enterprise Press, 2005.

GIL, A. C. Como elaborar projetos de pesquisa. 6. ed. São Paulo: Atlas, 2017.

GIL, A. C. Métodos e técnicas de pesquisa social. 5. ed. São Paulo: Atlas, 2008.

GLOOR, P. A. Coolfarming: turn your great ideas into the big thing. New York, NY, 2011.

GOMES, N. P.; FLORES, A. M. M., COHEN, S. Estudos de Tendências - contributo para uma abordagem de análise e gestão da cultura. In: ModaPalavra e-periódico, v. 11, no 22, 2018. Disponível em: http://www.revistas.udesc.br/index.php/modapalavra/article/view/ 11824. Acesso em: 20 jul. 2020.

LEAN ENTERPRISE INSTITUTE, (Comp.). Léxico Lean: glossário ilustrado para praticantes do Pensamento Lean. 2. ed. São Paulo: LEAN INSTITUTE BRASIL, 2007.

MAIOLI, F. M; PRESOTTO, J; PALMA, C. Coolhunting: Métodos e Práticas/ Maioli, Presotto \& palma: Milão, 2012.

MARCONI, M. de A; LAKATOS, E. M. Fundamentos de Metodologia Científica. $8^{\circ}$ ed. São Paulo: Atlas, 2017.

OSTERWALDER, A; PIGNEUR, Y. Business Model Generation: inovação em modelos de negócios. Atlas Books, 2010.

RAYMOND, M. Tendencias: que son, como identificarlas, en qué fijarnos, cómo leerlas. London: Promopress, 2010.

RECH, S. R.; CARDIM, V.C. O Processo da Pesquisa Qualitativa na Investigação de Tendências. In: Pesquisas em design, gestão e tecnologia de Têxtil e Moda./ Organizadores, Isabel Cristina Italiano ... [et al.] - São Paulo: EACH/USP, 2016.

RECH, S. R. Estudos do Futuro \& Moda: uma abordagem conceitual. ModaPalavra e-Periódico. v.6, n.11, p.93-100. jul-dez 2013. 
Disponível

em:

http://www.revistas.udesc.br/index.php/modapalavra/article/view/ 3477. Acesso em: 30 jul. 2020.

RECH, S. R; GOMES, N. P. Anatomia das tendências e o desenvolvimento de produtos de moda. In: $1^{\circ}$ Colóquio de Moda - $9^{\circ}$ Edição Internacional $3^{\circ}$ Congresso de Iniciação Científica em Design de Moda, 2016.2 Disponível em: http://www.coloquiomoda.com.br/anais/Coloquio\%20de\%20Moda $\% 20-\% 202016 / G T / G T 04-D E S I G N-E-P R O C E S S O S-D E-P R O D U C A O-$ EM-MODA/GT-04_ANATOMIA-DAS-TENDENCIAS.pdf. Acesso em: 30 jul. 2020.

RECH, S. R; SILVEIRA, I. Abordagem terminológica dos estudos de tendências. Anais... $13^{\circ}$ Colóquio de Moda- UNESP Bauru, São Paulo, 2017. Disponível em: https://www.academia.edu/35337128/ABORDAGEM_TERMINOL\%C 3\%93GICA_DOS_ESTUDOS_DE_TEND\%C3\%8ANCIAS. Acesso em: 14 jun. 2020.

SANCHES, M. C. F. Moda e projeto: estratégias metodológicas em Design. São Paulo: Estação das letras e Cores, 2017.

SANTOS, J. Sobre tendências e o espírito do tempo. São Paulo: Estação das Letras e Cores, 2017.

SILVEIRA, I. Procedimentos metodológicos de pesquisa: ciência e conhecimento. Florianópolis: 2018. (Apostila do Programa de Pós-Graduação em Moda, Mestrado Profissional em Design de Vestuário e Moda, PPGMODA/UDESC).

SEIVEWRIGHT, S. Pesquisa e design. Porto Alegre: Bookman, 2009.

TEZEL, A: KOSKELA, L; TZORTZOPULOS, P. The functions of Visual Management. Salford, UK: International Research Symposium. 2009.

TEIXEIRA, J. M. Gestão visual de projetos: Um modelo que utiliza o design para promover maior visualização ao processo de desenvolvimento de projetos. 2015. 330p. Proposta de Tese (Doutorado em Engenharia de Produção). Programa de PósGraduação em Engenharia de Produção, UFSC. Florianópolis, 2015. Disponível

em:

https://repositorio.ufsc.br/xmlui/handle/123456789/132982.

Acesso em 30 jul. 2020.

TEIXEIRA, J. M. Gestão visual de projetos: utilizando a informação para inovar/ Júlio Monteiro Teixeira. Rio de Janeiro: Atlas Books, 2018.

TEIXEIRA, J; SCHOENARDIE R.; MERINO, E.. Design Management: management levels and project development relations. In: Proceedings. Design Management: Toward a new era of innovation, Hong Kong, 2011, p. 194-201.

TEZEL, A.; KOSKELA, L.; TZORTZOPULOS, P. The functions of Visual Management. Salford, UK: International Research Symposium. 2009. 
TRENDWATCHING. Luciana Stein. Online, 2018. Disponível em: https://trendwatching.com/pt/about/luciana/. Acesso em: 28 jul. 2020.

WEBB, A. The Signals are Talking: why today's fringe is tomorrow's mainstream. New York: PublicAffairs, 2016.

ZAMBERLAN, L. et al. Pesquisa em ciências sociais aplicadas/ org. Luciano Zamberlan. Ijuí: Ed. Unijuí, 2014. 